\title{
Knowledge, attitudes and management skills of medical practitioners regarding weight management
}

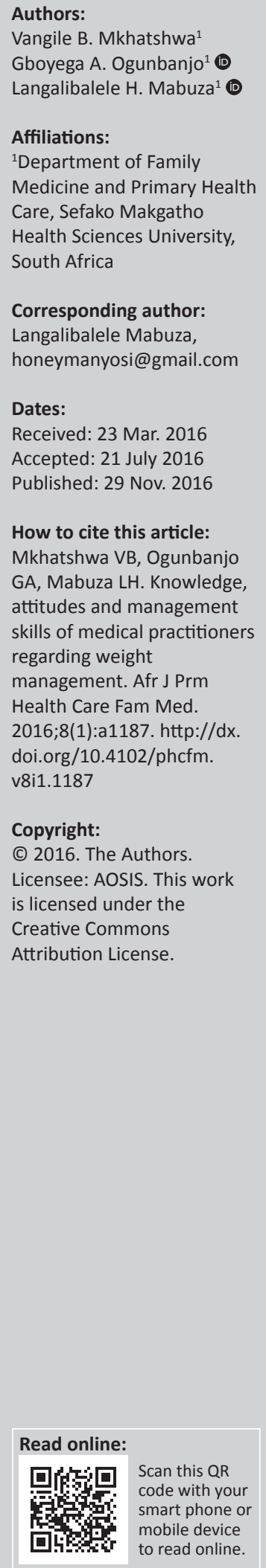

Authors:

gunbanjo ${ }^{1}$

Affiliations:

Department of Family

Care, Sefako Makgatho

Health Sciences University,

Langalibalele Mabuza,

Dates:

Accepted: 21 July 2016

How to cite this article:

Mkhatshwa VB, Ogunbanjo

skills of medical practitioners

regarding weight

2016;8(1):a1187. http://dx.

doi.org/10.4102/phcfm.

Copyright:

Licensee: AOSIS. This work

is licensed under the

reative Commons

to read online.
Background: Overweight and obesity have become a global problem. Health professionals are poorly prepared in weight management, which has an effect on their attitudes and management skills with regard to overweight and obese patients.

Aim and setting: To assess the knowledge, attitudes and management skills of medical practitioners regarding weight management at Odi District Hospital, Gauteng Province, South Africa.

Methods: We conducted a cross-sectional study on 48 medical practitioners at Odi Hospital between 01 October and 31 October 2013. A self-administered questionnaire was used to assess their knowledge, attitudes and management skills in weight management. The SPSS $^{\circledast}$ statistical software (Version 22) was used for data analysis. A $p<0.05$ was considered significant.

Results: Fifty medical practitioners were recruited, 48 consented to participate and 28 (58.3\%) were male. Their categories were community service doctors (3), medical officers (21), registrars (22) and others (2). Thirty-seven (77.1\%) never received training in weight management $(p<0.001)$. Thirty-two $(66.7 \%)$ regarded weight management as not confined to a dietician $(p<0.001)$ and $27(56.2 \%)$ regarded weight management as usually unsuccessful $(p=0.004)$. Forty-seven $(97.9 \%)$ provided lifestyle modifications and $43(89.6 \%)$ involved the patient's family in weight management $(p<0.001)$. More non-registrars [14 $(77.8 \%)]$ than registrars [8 (38.1\%)] measured the body mass index $(\mathrm{BMI})$ routinely $(p=0.013)$.

Conclusion: Few medical practitioners received training in weight management. They regarded weight management as usually unsuccessful and lacked confidence in the same owing to lack of training. They provided lifestyle modifications and involved the patient's family in weight management. Non-registrars measured the BMI routinely. There is a need for training in weight management at undergraduate and post-graduate levels.

\section{Background}

Overweight and obesity have become a global problem. ${ }^{1,2}$ In 2010, it was estimated that overweight and obesity caused 3.4 million deaths and a loss of $3.9 \%$ of years of life globally. ${ }^{3}$ It has been suggested that unabated overweight and obesity could lead to a global decline in life expectancy in the United States ${ }^{4}$ as a result of the associated risk factors and comorbidities, such as cardiovascular disease (CVD), diabetes (type 2) and various cancers. ${ }^{5}$ The concern about health risks associated with obesity has led member states of the World Health Organization (WHO) to adopt a voluntary target to halt the rise in obesity by $2025 .{ }^{6}$

In keeping with the global trend, in recent years there has also been a rise in the prevalence of overweight and obesity in the African continent. ${ }^{7,8}$ South Africa has been reported to have the highest prevalence of overweight and obesity in Sub-Saharan Africa (SSA), ${ }^{9}$ which has been ascribed to socio-cultural, socio-economic and behavioural factors. ${ }^{10}$ In the late eighties, obesity was defined as 'a condition of abnormal or excessive fat accumulation in adipose tissue, to the extent that health may be impaired' ${ }^{11}$

Parameters commonly used to measure overweight and obesity are the body mass index (BMI), waist circumference (WC) and waist-hip ratio (WHR). ${ }^{12}$ The BMI (defined as the individual's weight in kilograms, divided by the square of the height in metres $\left(\mathrm{kg} / \mathrm{m}^{2}\right)^{11}$ provides the most useful population-level measure of overweight and obesity, but it is a crude index as it does not account for the wide variation in body fat distribution. ${ }^{13}$ The BMI is classified as follows: underweight $\left(<18.5 \mathrm{~kg} / \mathrm{m}^{2}\right)$, normal range $\left(18.5-24.9 \mathrm{~kg} / \mathrm{m}^{2}\right)$, overweight $\left(25.0-29.9 \mathrm{~kg} / \mathrm{m}^{2}\right)$, 
obese class I (30.0-34.9 kg/m²), obese class II (35.0-39.9 kg/m²) and obese class III $\left(\geq 40.0 \mathrm{~kg} / \mathrm{m}^{2}\right) .{ }^{11}$

WC is a highly sensitive and specific measure of abdominal fat distribution and thus it is valuable for identifying overweight and obesity among patients at risk of developing metabolic complications. It is unrelated to height and correlates closely with BMI and WHR. ${ }^{11}$ The cut-off points are WC $>102 \mathrm{~cm}$ for men and $>88 \mathrm{~cm}$ for women. ${ }^{14} \mathrm{WC}$ has been proposed to be the best indicator in the measurement of central obesity, with excellent correlation with abdominal imaging and high association with CVD risk factors, especially diabetes. ${ }^{15,16}$ The WHR is also a measure of central obesity, since as the abdominal fat increases, so does the WC - relative to the hip girth. ${ }^{17}$ The cut-off points for defining central obesity are WHR > 1.0 in men and > 0.85 in women. ${ }^{11,13}$

The graded classification of overweight and obesity is valuable as it allows meaningful comparisons of weight status within and between populations, identification of individuals and groups at increased risk of morbidity and mortality as well as the identification of priorities for intervention at individual and community levels. ${ }^{11}$ In this study, we decided to use the BMI in the assessment of knowledge, attitudes and skills of medical practitioners as it is the most widely used measurement of overweight and obesity in all age groups. ${ }^{16}$

It has been shown that health professionals are poorly prepared to address overweight and obesity as a result of poor training in behavioural change strategies and the lack of experience in working within inter-professional teams. ${ }^{18}$ The central role of the primary health care practitioners (general practitioners and practice nurses) has been acknowledged in the United Kingdom and Scotland, resulting in the formulation of guidelines on overweight/obesity prevention and management at primary care level. ${ }^{19}$ The advantage of this strategy is the population coverage and continuity of care and trust built over a number of encounters, ${ }^{20}$ and the practical application of the primary care principle that every patient encounter should be regarded as an opportunity for health promotion..$^{21}$ The Royal College of Physicians in the United Kingdom has issued a report on the training of general practitioners in weight management. The report has indicated that the training was minimal and poorly coordinated - 'a reflection of lack of focus on obesity throughout medical training as a whole'. ${ }^{22}$

It has been shown that health care practitioners' practice in the management of patients with overweight and obesity is influenced by their attitudes. ${ }^{19}$ In a study comparing weight bias in 2001 versus 2013 in the management of overweight and obesity among weight management specialists, it was demonstrated that there has been a paradigm shift from implicit (unconsciously expressed) to explicit (consciously expressed) anti-fat bias. The biases were expressed by the medical practitioners as bad, lazy, stupid and worthless. ${ }^{23}$ The weight of the health care practitioner may also influence their attitudes towards management of overweight and obesity as an overweight and obese practitioner would be less inclined to advise on weight management. In addition, an overweight and obese patient may not take seriously advice from a practitioner of similar weight. ${ }^{19}$

Literature on the training of health care practitioners in general, and medical practitioners in particular, in Africa is lacking. Most of the studies report on nutrition and management of patients with overweight and obesity. ${ }^{24,25}$ However, in South Africa, Malan, Mash and Everett-Murphy published work on development of a training programme to counsel patients on risky behaviour (including physical inactivity and unhealthy diet), ${ }^{26}$ and evaluation of a training programme for primary care providers on brief behavioural change counselling (BBCC) on risk factors for noncommunicable diseases which could result from overweight and obesity. ${ }^{27}$

The aim of this study was to determine the knowledge, attitudes and management skills of medical practitioners in the management of overweight and obese patients at Odi District Hospital in the Gauteng Province. At the time of the study, the medical practitioners at the hospital comprised three categories: community service doctors, medical officers (MOs) and registrars (residents). In the South African health care system, a 2-year internship programme is followed by 1 year of community service, hence the title of community service doctor. The medical practitioner who has completed his/her community service year and is practicing in the public service is referred to as a MO. A registrar is a medical practitioner who is pursuing specialist training in a particular medical discipline; General Surgery, Family Medicine, and so on. ${ }^{28}$ In this study, all the registrars were trainees in Family Medicine.

\section{Research methods and design Study area and period}

We conducted a study among medical practitioners at Odi District Hospital, Gauteng province, between 01 October and 31 October 2013.

\section{Study design}

This was a cross-sectional study.

\section{Study population}

At the time of the study, there were 50 medical practitioners at the hospital. They were all eligible for the study.

\section{Sampling procedure}

Of the 50 medical practitioners eligible for the study, only 48 medical practitioners completed the questionnaire (response rate: $96 \%$ ). The inclusion criteria were employment at Odi District Hospital, on a full-time or sessional basis. The period of the doctor's employment at the hospital to qualify for 
inclusion was set at a minimum of 6 months, which the researchers regarded as adequate exposure for the medical practitioner to field questions in the questionnaire about his / her experience at the hospital. Other categories of health care professionals - pharmacists, for example - were excluded from the study. We recruited the medical practitioners on individual basis. The principal researcher outlined the aim, objectives and the study processes to each medical practitioner.

There were four categories of medical practitioners in the hospital: community service doctors (3), MOs (21), registrars (22) and others (2) - the latter referring to those in administrative posts, for example, the clinical manager.

\section{Data collection}

A self-administered questionnaire was used to assess their knowledge, attitudes and management skills about overweight and obesity. The questionnaire was derived from a validated questionnaire. ${ }^{29}$ Given that a questionnaire developed in a different time, country or cultural context may not be a valid measure in a different population, questions that were not applicable in our setting, for example, 'Pharmacotherapy for weight-management strategies reported by physicians ${ }^{\prime 30}$ were removed since the medical practitioners in our setting did not prescribe medication for weight management. We piloted the questionnaire on five medical practitioners at Jubilee District Hospital located 50 $\mathrm{km}$ from the study site to establish the degree to which the questions elicited the same response among the respondents. Furthermore, at the point of questionnaire administration, the researcher requested each respondent to complete all the questions in that sitting rather than having another completion opportunity in future settings, to minimise data entry errors. ${ }^{30,31}$ Data collected in the pilot study were excluded from the main study. However, the data collected through our questionnaire was not compared with data collected through similar questionnaires in other studies.

Regarding their knowledge on overweight and obesity, they were asked to indicate if they agreed, disagreed or were unsure about statements relating to overweight and obesity as a national problem in South Africa, medical practitioners' role in overweight and obesity prevention, overweight and obesity definition in terms of the BMI, the goal in the management of overweight and obesity and the status of overweight and obesity management at Odi District Hospital in particular.

Regarding their attitudes towards management of patients with overweight or obesity, they were assessed on the basis of being a responsible professional in the management of overweight or obesity, the adequacy of the training on overweight and obesity management at undergraduate level, the level of health care at which overweight and obesity should primarily be managed, their confidence in the management of overweight and obesity in adult and paediatric patients, as well as their attitudes towards the success of overweight and obesity management.

Regarding their management skills with regard to overweight and obese patients, they were asked to indicate the extent to which they measured the BMI of patients with chronic diseases and overweight and obesity, provided lifestyle modifications and involved the patient's family in the management of the patient's overweight and obesity. Lifestyle modifications include low-calorie, low-fat diet and 150 minutes/week of physical activity. ${ }^{32}$ At the time of the study, BMI measurement was the responsibility of the medical practitioner.

\section{Data analysis}

Baseline characteristics were presented as descriptive data in absolute numbers and frequencies. A comparison through bivariate data analysis was made between those who had received training in the management of overweight and obesity (per medical practitioners' category) and those who had not. Training in overweight/obesity referred to ever attending a short course or a workshop on the management of overweight and obesity, including during undergraduate medical training. A similar data analysis process was conducted to determine the level of the medical practitioners' knowledge, attitudes and management skills in the management of overweight/obesity. Finally, a comparison was made between medical practitioners who were pursuing a post-graduate training in Family Medicine (registrars) versus those who were not (non-registrars), in relation to the management of overweight and obesity among patients. The SPSS ${ }^{\circledR}$ statistical software (Version 22) was used for data analysis. A $p<0.05$ was considered significant.

\section{Ethical considerations}

The Medunsa Research and Ethics Committee (MREC) approved the study and allocated the clearance certificate number MREC/M/27/2013:PG. The clinical manager at Odi Hospital gave permission to conduct the study at the site. All respondents provided written informed consent for the study. Participation was voluntary and the respondents were informed of their right to withdraw from the study at any stage without negative consequences. Anonymity and confidentiality of the collected data were also confirmed.

\section{Results}

In Table 1, the baseline characteristics of the participants are documented and they show that the majority of the medical practitioners $(21 ; 43 \%)$ were aged between 31 and 40 years. There were more male medical practitioners (28; 58.3\%). Most of them $(34 ; 70.8 \%$ ) had graduated between the year 2001 and 2011. The MOs and registrars constituted the highest percentage $(89.6 \%)$.

Table 2 shows that among the three community service doctors in the hospital, two $(66.7 \%)$ had received training on 
the management of overweight and obesity (after qualifying as medical practitioners). The majority of the MOs (18; $85.7 \%$ ) and registrars $(17 ; 77.3 \%)$ responded that they had not received training in the management of overweight and obesity. In both cases, there was a significant difference between those who responded that they had received training versus those who reported to the contrary $(p<0.001)$. When all the medical practitioner categories were pooled together, there was a statistically significant difference between those who indicated that they had

TABLE 1: Baseline characteristics $(n=48)$.

\begin{tabular}{lcc}
\hline Baseline characteristics & Frequency & Percentage \\
\hline Age (Years) & 7 & 14.6 \\
$21-30$ & 21 & 43.7 \\
$31-40$ & 12 & 25.0 \\
$41-50$ & 7 & 14.6 \\
$51-60$ & 1 & 2.1 \\
Not indicated & 40.3 & - \\
Mean & $29-60$ & - \\
Range & 8.6 & - \\
Standard deviation & & \\
Gender & 18 & 37.5 \\
Female & 28 & 58.3 \\
Male & 2 & 4.2 \\
Not indicated & & \\
Graduation year grouped & 4 & 8.3 \\
1982-1990 & 9 & 18.8 \\
1991-2000 & 34 & 70.8 \\
2001-2011 & 1 & 2.1 \\
Not indicated & & 4.2 \\
Professional categories & 21 & 6.2 \\
Community service doctor & 22 & 45.8 \\
Medical officer & & \\
Registrar & & \\
Other & & \\
\hline
\end{tabular}

Source: Odi District Hospital records (2013) and medical practitioners received training on overweight and obesity management $(11 ; 22.9 \%)$ versus those who indicated that they had not $(37 ; 77.1 \%),(p<0.001)$.

Table 3 shows that 47 (97.9\%) medical practitioners agreed with the statement that overweight and obesity was a problem in South Africa. Medical practitioners demonstrated poor knowledge on the classification of BMI $(p<0.05)$. Ten $(20.8 \%)$ medical practitioners were unsure whether a sustained $10 \%$ body weight loss over 6 months was an important goal in the management of overweight and obesity. ${ }^{33}$ Forty $(83.3 \%)$ medical practitioners disagreed that overweight and obesity management was effective at Odi Hospital.

Table 4, which reflects medical practitioners' attitudes, demonstrates that $32(66.7 \%)$ medical practitioners disagreed that management of overweight and obesity was the responsibility of a dietician versus 10 (20.8\%) who agreed, with a statistically significant difference between the two groups $(p<0.001)$. Forty-five $(94.0 \%)$ medical practitioners disagreed with the statement that overweight and obesity management is the sole responsibility of a specialist in internal medicine. Thirty-seven (77.1\%) medical practitioners disagreed that the undergraduate training on overweight and obesity management was adequate for them versus two $(4.1 \%)$ who agreed $(p<0.001)$. Twenty-two $(45.8 \%)$ medical practitioners agreed with the statement that overweight and obesity should be managed at the primary health care level versus $17(35.4 \%)$ who disagreed $(p=0.298)$.

Medical practitioners did not differ significantly $(p=0.308)$ between those who were confident on the management of overweight and obesity among adult patients (21;43.7\%)

TABLE 2: Proportion of medical practitioners by professional category on overweight/obesity management training.

\begin{tabular}{|c|c|c|c|c|}
\hline \multirow[t]{2}{*}{ Professional category $(n=48)$} & \multicolumn{4}{|c|}{ Received training on overweight/obesity management } \\
\hline & Yes & No & Total & $p^{*}$ \\
\hline Community service doctor & $2(66.7)$ & $1(33.3)$ & $3(100.0)$ & 0.412 \\
\hline Medical officer & $3(14.3)$ & $18(85.7)$ & $21(100.0)$ & $<0.001$ \\
\hline Registrar & $5(22.7)$ & $17(77.3)$ & $22(100.0)$ & $<0.001$ \\
\hline Other & $1(50.0)$ & $1(50.0)$ & $2(100.0)$ & 0.529 \\
\hline Total & 11 (22.9) & 37 (77.1) & $48(100.0)$ & $<0.001$ \\
\hline
\end{tabular}

Source: Odi District Hospital records (2013) and medical practitioners

*, Fisher's exact test.

TABLE 3: Medical practitioners' knowledge on overweight/obesity.

\begin{tabular}{|c|c|c|c|c|c|}
\hline \multirow[t]{2}{*}{ Statements on knowledge assessment } & \multicolumn{5}{|c|}{ Medical practitioners' knowledge on overweight/obesity } \\
\hline & Agree & Disagree & Unsure & Total & $p^{*}$ \\
\hline Overweight/obesity is a problem in South Africa. $n(\%)$ & 47 (97.9) & $1(2.1)$ & $0(0.0)$ & $48(100.0)$ & $<0.001$ \\
\hline The role of medical practitioners in the prevention of overweight/obesity is limited. $n(\%)$ & $20(41.7)$ & $26(54.2)$ & $2(4.1)$ & $48(100.0)$ & 0.219 \\
\hline Most people can reduce their weight and maintain it. $n(\%)$ & $24(50.0)$ & $20(41.7)$ & $4(8.3)$ & $48(100.0)$ & 0.412 \\
\hline Obesity is a $\mathrm{BMI}>25 \mathrm{~kg} / \mathrm{m}^{2} . n(\%)$ & $29(61.7)$ & $17(36.2)$ & $2(4.1)$ & $48(100.0)$ & 0.014 \\
\hline Class I obesity is a BMI $=25-29 \mathrm{~kg} / \mathrm{m}^{2}$. & $29(61.7)$ & 15 (31.9) & $4(8.3)$ & $48(100.0)$ & 0.004 \\
\hline Class II obesity is a BMI $=30-34.9 \mathrm{~kg} / \mathrm{m}^{2} . n(\%)$ & $32(66.7)$ & $12(25.0)$ & $4(8.3)$ & $48(100.0)$ & $<0.001$ \\
\hline A sustained $10 \%$ body weight loss is an important goal in the management of overweight/obesity. $n(\%)$ & $32(66.7)$ & $6(12.5)$ & $10(20.8)$ & $48(100.0)$ & $<0.001$ \\
\hline Anti-overweight/obesity medication should be started from a BMI of $25 \mathrm{~kg} / \mathrm{m}^{2} . n(\%)$ & $5(10.4)$ & $38(79.2)$ & $5(10.4)$ & $48(100.0)$ & $<0.001$ \\
\hline Overweight/obesity management is effective at Odi Hospital. $n(\%)$ & $1(2.1)$ & $40(83.3)$ & $7(14.6)$ & $48(100.0)$ & $<0.001$ \\
\hline
\end{tabular}


versus those who were not (26;54.2\%). They differed significantly with regard to management of overweight and obesity among children $(p<0.001)$. There were more medical practitioners who agreed $(22 ; 45.8 \%)$ that management of overweight and obesity was difficult for medical practitioners versus those who disagreed (17; $35.4 \%)$, but there was no statistically significant difference between the two groups. Twenty-seven (56.2\%) medical practitioners agreed with the statement that overweight and obesity management was usually unsuccessful, while $13(27.1 \%)$ disagreed $(p=0.004)$. The same results were obtained for the statement that medical practitioners lacked interest in the management of overweight and obesity.

The recording of patients' weight as part of the management of patients with chronic diseases was done most of the time by $15(31.3 \%)$ medical practitioners, while 28 (58.3\%) indicated that they did so occasionally ( $p=0.008)$. Twentynine $(60.4 \%)$ medical practitioners indicated that they recorded patients' weight as part of opportunity screening for overweight and obese patients versus $11(22.9 \%)$ who did so occasionally $(p<0.001)$. Twenty-four (50\%) medical practitioners indicated that they measured the weight of overweight and obese patients routinely versus 17 (35\%) who did so occasionally - but there was no statistical difference between the two groups $(p=0.150)$.

Provision of lifestyle modifications as part of the management of patients with overweight and obesity was done most of the time by 47 (97.9\%) medical practitioners versus $1(2.1 \%)$ who did so occasionally $(p<0.001)$. Involvement of the patient's family members in the management of the patient's overweight and obesity was done most of the time by 43 (89.6\%) medical practitioners, while $3(6.3 \%)$ did so occasionally $(p<0.001)$ (Table 5).

Table 6 shows that there were significantly more nonregistrars 11 (52.4\%) versus registrars 4 (20.0\%) who indicated that they recorded weight as part of management of patients with chronic diseases $(p=0.033)$. There were also significantly more non-registrars $14(77.8 \%)$ versus registrars $8(38.1 \%)$ who measure weight for overweight patients routinely $(p=0.013)$. There were no other significant differences in knowledge, attitudes and practice relating to the management of overweight and obesity between registrars and nonregistrars $(p>0.050)$.

\section{Discussion}

This study has shown that there was a significantly fewer number of medical practitioners who had received training in weight management. A high percentage (97.9\%) of the medical practitioners were aware that overweight and obesity are a problem in South Africa, but $>60 \%$ of them did not know the classification of overweight and obesity according to the BMI. Their attitudes were that weight management was not primarily the responsibility of a dietician or a specialist in internal medicine. However, they were not confident in the management of overweight and obesity in children. They regarded weight management as usually unsuccessful and regarded themselves as lacking interest in weight management. They occasionally (versus 'most of the time') practised BMI measurement but provided lifestyle modifications and involved the patient's family in weight management most of the time. More non-registrars compared with registrars measured patients' BMI as part of

TABLE 4: Medical practitioners' attitudes towards management of overweight/obesity $(n=48)$.

\begin{tabular}{|c|c|c|c|c|c|}
\hline \multirow[t]{2}{*}{ Statements on attitudes assessment } & \multicolumn{5}{|c|}{ Medical practitioners' attitudes towards management of overweight/obesity } \\
\hline & Agree & Disagree & Neutral & Total & $p^{*}$ \\
\hline Overweight/obesity management is mainly the responsibility of a dietician. & $10(20.8)$ & $32(66.7)$ & $6(12.5)$ & $48(100.0)$ & $<0.001$ \\
\hline Overweight/obesity management is the sole responsibility of a specialist in internal medicine. & $0(0)$ & $45(94.0)$ & $3(6.3)$ & $48(100.0)$ & $<0.001$ \\
\hline Overweight/obesity management was adequately covered during undergraduate medical training. & $2(4.1)$ & $37(77.1)$ & $9(18.8)$ & $48(100.0)$ & $<0.001$ \\
\hline Overweight/obesity should be managed at the primary health care level. & $22(45.8)$ & $17(35.4)$ & $9(18.8)$ & $48(100.0)$ & 0.298 \\
\hline I am confident of managing overweight/obesity in adult patients. & $21(43.7)$ & $26(54.2)$ & $1(2.1)$ & $48(100.0)$ & 0.308 \\
\hline I am confident of managing overweight/obesity in children. & $12(25.0)$ & $35(72.9)$ & $1(2.1))$ & $48(100.0)$ & $<0.001$ \\
\hline Management of obese patients is difficult for medical practitioners. & $22(45.8)$ & $17(35.4)$ & $9(18.8)$ & $48(100.0)$ & 0.298 \\
\hline Overweight/obesity management is usually unsuccessful. & $27(56.2)$ & $13(27.1)$ & $8(16.7)$ & $48(100.0)$ & 0.004 \\
\hline Medical practitioners lack interest in the management of overweight/obesity. & $27(56.2)$ & $13(27.1)$ & $8(16.7)$ & $48(100.0)$ & 0.004 \\
\hline
\end{tabular}

Source: Medical practitioners at Odi District Hospital

*, Fisher's exact test.

TABLE 5: Medical practitioners' management skills for patients with overweight/obesity $(n=48)$.

\begin{tabular}{|c|c|c|c|c|c|}
\hline \multirow[t]{2}{*}{ Statements on management skills assessment } & \multicolumn{5}{|c|}{ Medical practitioners' skills for patients with overweight/obesity } \\
\hline & Most of the time & Occasionally & Never & Total & $p^{*}$ \\
\hline I measure the BMI as part of management of patients with chronic disease. $n(\%)$ & $15(31.3)$ & $28(58.3)$ & $5(10.4)$ & $48(100.0)$ & 0.008 \\
\hline I measure the BMI as part of opportunistic screening on overweight/obese patients. $n$ (\%) & $11(22.9)$ & $29(60.4)$ & $8(16.7)$ & $48(100.0)$ & $<0.001$ \\
\hline I measure the BMI of overweight/obese patients as routine. $n(\%)$ & $24(50.0)$ & $17(35.4)$ & $7(14.6)$ & $48(100.0)$ & 0.150 \\
\hline I provide lifestyle modifications as part of management of patients with overweight/obesity. $n(\%)$ & $47(97.9)$ & $1(2.1)$ & $0(0)$ & $48(100.0)$ & $<0.001$ \\
\hline I involve family members in the management of patients with overweight/obesity. $n$ (\%) & $43(89.6)$ & $3(6.3)$ & $2(4.1)$ & $48(100.0)$ & $<0.001$ \\
\hline
\end{tabular}

Source: Medical practitioners at Odi District Hospital

*, Fisher's exact test. 
TABLE 6: Comparison of knowledge, attitudes and skills regarding overweight/obesity management between registrars and non-registrars.

\begin{tabular}{|c|c|c|c|c|}
\hline Statement & Response & Registrars $n(\%)$ & Non-registrars $n(\%)$ & $p^{*}$ \\
\hline \multicolumn{5}{|l|}{ Knowledge } \\
\hline Overweight/obesity is a problem in South Africa $(n=44)$. & $\begin{array}{l}\text { Yes } \\
\text { No }\end{array}$ & $\begin{array}{l}22(100) \\
0(0.0)\end{array}$ & $\begin{array}{l}23(95.8) \\
1(4.2)\end{array}$ & $\begin{array}{c}0.338 \\
-\end{array}$ \\
\hline Obesity is a BMI $>25 \mathrm{~kg} / \mathrm{m}^{2}(n=44)$. & $\begin{array}{l}\text { Yes } \\
\text { No }\end{array}$ & $\begin{array}{l}11(50.0) \\
11(50.0)\end{array}$ & $\begin{array}{l}16(72.7) \\
6(27.3)\end{array}$ & 0.126 \\
\hline Class I obesity is a BMI $=25-29.9 \mathrm{~kg} / \mathrm{m}^{2}(n=43)$. & $\begin{array}{l}\text { Yes } \\
\text { No }\end{array}$ & $\begin{array}{l}11(52.4) \\
10(47.6)\end{array}$ & $\begin{array}{l}17(77.3) \\
5(22.7)\end{array}$ & $\begin{array}{c}0.090 \\
-\end{array}$ \\
\hline $\begin{array}{l}\text { A sustained } 10 \% \text { body weight loss over } 6 \text { months is an important goal in the management of } \\
\text { overweight/obesity }(n=36) \text {. }\end{array}$ & $\begin{array}{l}\text { Yes } \\
\text { No }\end{array}$ & $\begin{array}{l}13(81.3) \\
3(18.7)\end{array}$ & $\begin{array}{l}18(90.0) \\
2(10.0)\end{array}$ & $\begin{array}{c}0.457 \\
-\end{array}$ \\
\hline \multicolumn{5}{|l|}{ Attitudes } \\
\hline Medical practitioners have a limited role in the management of overweight/obesity $(n=44)$. & $\begin{array}{l}\text { Yes } \\
\text { No }\end{array}$ & $\begin{array}{c}8(38.1) \\
13(61.9)\end{array}$ & $\begin{array}{l}12(52.2) \\
11(47.8)\end{array}$ & $\begin{array}{c}0.354 \\
-\end{array}$ \\
\hline Management of overweight/obesity is the responsibility of a dietician $(n=41)$. & $\begin{array}{l}\text { Yes } \\
\text { No }\end{array}$ & $\begin{array}{c}4(22.2) \\
14(77.8)\end{array}$ & $\begin{array}{c}5(21.7) \\
18(78.3)\end{array}$ & $\begin{array}{c}0.971 \\
-\end{array}$ \\
\hline I am confident of managing overweight/obesity in adult patients $(n=46)$. & $\begin{array}{l}\text { Yes } \\
\text { No }\end{array}$ & $\begin{array}{l}11(52.4) \\
10(47.6)\end{array}$ & $\begin{array}{l}10(41.7) \\
14(58.3)\end{array}$ & $\begin{array}{c}0.477 \\
-\end{array}$ \\
\hline I am confident of managing overweight/obesity in children $(n=45)$. & $\begin{array}{l}\text { Yes } \\
\text { No }\end{array}$ & $\begin{array}{c}5(23.8) \\
16(76.2)\end{array}$ & $\begin{array}{c}3(15.0) \\
17(85.0)\end{array}$ & $\begin{array}{c}0.482 \\
-\end{array}$ \\
\hline \multicolumn{5}{|l|}{ Management skills } \\
\hline I measure the BMI as part of management of patients with chronic disease $(n=41)$. & $\begin{array}{l}\text { Yes } \\
\text { No }\end{array}$ & $\begin{array}{c}4(20) \\
16(80)\end{array}$ & $\begin{array}{l}11(52.4) \\
10(47.6)\end{array}$ & $\begin{array}{c}0.033 \\
-\end{array}$ \\
\hline I measure the BMI of overweight patients as routine $(n=39)$. & $\begin{array}{l}\text { Yes } \\
\text { No }\end{array}$ & $\begin{array}{c}8(38.1) \\
13(61.9)\end{array}$ & $\begin{array}{c}14(77.8) \\
4(22.2)\end{array}$ & $\begin{array}{c}0.013 \\
-\end{array}$ \\
\hline I measure the BMI of obese patients as routine $(n=38)$. & $\begin{array}{l}\text { Yes } \\
\text { No }\end{array}$ & $\begin{array}{l}11(47.6) \\
10(47.6)\end{array}$ & $\begin{array}{l}11(64.7) \\
6(35.3)\end{array}$ & $\begin{array}{c}0.450 \\
-\end{array}$ \\
\hline The weight management programme always includes referring to a dietician $(n=46)$. & $\begin{array}{l}\text { Yes } \\
\text { No }\end{array}$ & $\begin{array}{c}15(68.2) \\
7(31.8)\end{array}$ & $\begin{array}{l}20(87.0) \\
3(13.0)\end{array}$ & $\begin{array}{c}0.134 \\
-\end{array}$ \\
\hline I always include advice on physical activity in weight management $(n=44)$. & $\begin{array}{l}\text { Yes } \\
\text { No }\end{array}$ & $\begin{array}{c}22(100.0) \\
0(0)\end{array}$ & $\begin{array}{c}24(100.0) \\
0(0)\end{array}$ & $\begin{array}{c}0.110 \\
-\end{array}$ \\
\hline
\end{tabular}

Source: Medical practitioners at Odi District Hospital

*, Fisher's exact test.

the management of patients with chronic diseases and as routine for overweight patients.

In our study, almost all the medical practitioners (97.9\%) were aware that overweight and obesity was a problem in South Africa. Indeed, a study has shown that in South Africa, the prevalence of overweight and obesity increased significantly from $23.5 \%$ in 2008 to $27.2 \%$ in $2012(p<0.001) .{ }^{34}$ More than $60 \%$ of the medical practitioners demonstrated good knowledge on the classification of BMI. This was higher than the percentage obtained by Block et al. in their survey of residents in internal medicine that revealed that only $40 \%$ displayed good knowledge about BMI ${ }^{35}$ In a study conducted in Hungary on the evaluation of the knowledge, practice and attitudes of medical practitioners, it was found that awareness of the diagnostic threshold for overweight and obesity in terms of the BMI was 51\% among general practitioners (an equivalent of MOs in our study) and $90 \%$ among residents (an equivalent of registrars in our study).

In this study, two-thirds of the medical practitioners indicated that overweight and obesity management was not primarily the responsibility of a dietician, and about nine-in-ten disagreed that overweight/obesity management was solely the responsibility of a specialist in internal medicine. Indeed, the management of overweight and obesity has been found to have a wider objective than weight loss alone - it includes mortality risk reduction and improvement of the quality of life. ${ }^{36}$ Therefore, appropriate management of overweight and obesity should be interdisciplinary, including lipid profile control, blood pressure management, evaluation of respiratory disorders (e.g. sleep apnoea syndrome), pain control for arthritis and management of psychosocial disturbances (e.g. eating disorders). ${ }^{35}$

More than three-quarters of the medical practitioners disagreed that overweight and obesity management were adequately covered at undergraduate medical training. In its report referred to earlier in this article, The Royal College of Physicians has indicated that the minimal and poorly coordinated training of medical practitioners on weight management reflected lack of training on overweight and obesity at undergraduate level..$^{23}$

More medical practitioners (45.8\%) expressed difficulty in managing overweight and obesity. This has been shown to be related mainly to three barriers in the initiation of the topic: lack of competence on overweight and obesity care, concern about possible negative consequences elicited by introducing the topic to patients during a consultation and time constraints and limited resources to raise the sensitive topic, ${ }^{37}$ especially if the overweight and obesity are not the presenting complaint in a given consultation. Since Odi District Hospital is a primary health care facility with a large workload of patients, the authors are of the opinion that the medical practitioners had a similar explanation for the difficulty they expressed in the management of overweight and obesity.

Schmidt et al. in their study on how weight management specialists treated overweight and obesity before 2012 discovered that $99 \%$ of them used stimulant medication (amphetamines, diethylpropion and phendimetrazine) 
without time limit on amphetamines (50\%) and at higher doses than recommended in the package insert. ${ }^{38}$ In our study, we did not require the medical practitioners to provide us with the medication names. According to the knowledge of the authors, weight control medication is excluded from the medical formulary of the South African public sector health care facilities. ${ }^{39}$ Therefore, at Odi District Hospital, each practitioner would refer patients in need mainly to the private sector facilities. The main emphasis on weight management in the public sector would be lifestyle modifications. $^{28}$

More than half of the medical practitioners (54.2\%) indicated that they were not confident on the management of overweight and obesity among adult patients, in keeping with the study by Block et al. where medical practitioners expressed negative opinions about their skills for treating obese patients. ${ }^{35}$ The percentage was significantly higher (72.9\%) among medical practitioners who expressed lack of confidence in the management of childhood overweight and obesity. Several studies have indicated that overweight and obesity treatment could improve in primary care by supporting practitioners to identify and manage paediatric patients..$^{40,41,42}$

In this study, about half (56.2\%) of the medical practitioners viewed management of overweight and obesity as usually unsuccessful, in keeping with a study by Ferrante et al. in their survey of practices and attitudes of family physicians in New Jersey (USA), where $51 \%$ of the family physicians regarded treatment for overweight and obesity as often ineffective. ${ }^{43}$ Nevertheless, health care providers need to show interest in weight management as it has been demonstrated that patient behavioural change increases with provider encouragement and goal setting. ${ }^{44}$

Significantly, more medical practitioners (58\%) recorded patients' BMI occasionally (versus 31\% who indicated 'most of the time' as part of the management of patients with chronic diseases. Overweight and obesity should be included among the list of chronic diseases as it is a component of the metabolic syndrome, the other components being an increased WC, elevated triglycerides, reduced high-density lipoprotein (HDL) cholesterol, elevated blood pressure and elevated fasting glucose. ${ }^{45}$ Successful overweight and obesity management, as chronic diseases, has been shown to improve the quality of life. This has been demonstrated in the study by Sarwer et al. conducted at the University of Pennsylvania (United States) where a mean weight loss of $3.9 \pm 0.3 \mathrm{~kg}$ was associated with improvement in the quality of life. ${ }^{45}$

Our study demonstrated that almost $98 \%$ of medical practitioners indicated that they provided lifestyle modifications as part of the management of patients with overweight and obesity. The effect of this intervention, albeit only verbal, should not be underestimated as it has been shown that advice on losing weight by a health care professional was associated with the desire and attempt to lose weight $(\mathrm{OR}=3.71$ and $\mathrm{OR}=3.53,95 \% \mathrm{CI}$, respectively) among overweight and obese British adults - independent of demographic and weight status. ${ }^{46}$

Almost $90 \%$ of medical practitioners indicated that they involved the patient's family members most of the time in the management of the patient's overweight and obesity. It has been shown that social support from family and friends is effective in assisting patients to shed weight and prevent weight gain. ${ }^{47,48}$

There were significantly more non-registrars (52.4\%) versus registrars $(20.0 \%)$ who indicated that they measured patients $\mathrm{BMI}$ as part of management of patients with chronic diseases, and also significantly more non-registrars $(77,8 \%)$ who measured the BMI among overweight patients routinely. Weight loss in overweight and obese patients has been associated with improvement of chronic conditions such as asthma, ${ }^{49}$ CVD (including heart failure), ${ }^{50}$ and diabetes mellitus. ${ }^{51}$

Regarding BMI measurement, we would have expected an opposite finding in which registrars would have performed this measurement more than non-registrars, given that the former were undergoing post-graduate training in patient care. The explanation for this opposite finding is unclear to the authors. However, we are aware of the studies by Ferrante et al. in which they reported that family physicians expressed difficulty in conducting a physical examination (including weight management) in obese patients, ${ }^{43}$ and Rurik et al. who reported inconsistency among family physicians in Hungary in measuring patients' anthropomorphic indices. ${ }^{52}$

\section{Recommendations}

Given that overweight and obesity have become a global problem, the undergraduate medical curriculum planners should incorporate training in weight management in the undergraduate curriculum. Overweight and obesity should be treated as a non-communicable disease at undergraduate and post-graduate levels and in the medical practitioners' fields of practice. Weight management should be a collaborative interdisciplinary team effort. Given the high percentage of medical practitioners who indicated lack of training in weight management, it is recommended that short courses and continuing medical education workshops be arranged on a mandatory basis for all medical practitioners. Such in-service training opportunities may address the lack in knowledge, correct attitudes and empower the medical practitioners to correctly apply the knowledge thus obtained.

\section{Strengths and limitations}

To our knowledge, the study is the first to explore the knowledge, attitudes and management skills of medical practitioners regarding weight management in the whole of Tshwane District. However, the study was conducted in a single health care facility, which limits the generalisability of the study findings. The study was conducted among 48 (out of the available 50) medical practitioners who consented to participate 
at the study setting. Therefore, it is acknowledged that the sample size was relatively small. The data relating to the medical practitioners' knowledge, attitudes and management skills were self-reported. Consequently, inaccuracies in the medical practitioners' reporting cannot be excluded.

\section{Conclusion}

The number of medical practitioners who had received training in weight management was significantly small. Almost all of the medical practitioners were aware of the problem of overweight and obesity in South Africa, but $>60 \%$ did not know the BMI classification of overweight and obesity. Their attitudes were that weight management was not mainly the responsibility of a dietician and not the sole responsibility of a specialist in internal medicine. Nevertheless, they were not confident in the management of overweight and obesity in children. They regarded weight management as usually unsuccessful and regarded themselves as lacking interest in weight management. They occasionally practiced BMI measurement but provided lifestyle modifications and involved the patient's family in weight management most of the time. Non-registrars measured patients' weight as part of the management of patients with chronic diseases and measured patients' BMI routinely - significantly more than the registrars.

\section{Acknowledgements}

The researchers are grateful for the contributions of Professor HS Schoeman towards the study data analyses. This study was conducted in partial fulfilment of the requirements for the award of the Master of Medicine (Family Medicine) degree for the first author at the University of Limpopo, Medunsa Campus, Pretoria, South Africa [now known as Sefako Makgatho Health Sciences University (SMU)].

\section{Competing interests}

The authors declare that they have no financial or personal relationship(s) that may have inappropriately influenced them in writing this article.

\section{Authors' contribution}

V.B.M. conceptualised the research idea. G.A.O. supervised the Master of Medicine (Family Medicine) registrar. L.H.M. drafted the manuscript. V.B.M. and G.A.O. reviewed the draft manuscript and G.A.O. edited the final draft. All authors approved the final manuscript.

\section{References}

1. Rennie KL, Jebb SA. Prevalence of overweight and obesity in Great Britain. Obes Rev. 2005;6:11-12. http://dx.doi.org/10.1111/j.1467-789X.2005.00164.x

2. Wang Y, Beydoun MA. The obesity epidemic in the United States - Gender, age, socioeconomic, racial/ethnic, and geographic characteristics: A systematic review and meta-regression analysis. Epidemiol Rev. 2007;29:6-28. http://dx.doi. org/10.1093/epirev/mxm007

3. Lim SS, Vos T, Flaxman AD, et al. A comparative risk assessment of burden of disease and injury attributable to 67 risk factors and risk factor clusters in 21 regions, 19902010: A systematic analysis for the Global Burden of Disease Study 2010. Lancet. 2012;380:2224-2260. http://dx.doi.org/10.1016/S0140-6736(12)61766-8
4. Olshansky SJ, Passaro DJ, Hershow RC, et al. A potential decline in life expectancy in the United States in the 21st century. N Engl J Med. 2005;352:1138-1145. http://dx.doi.org/10.1056/NEJMsr043743

5. Dalal S, Beunza JJ, Volmink J, et al. Non-communicable diseases in sub-Saharan Africa: What we know now. Int J Epidemiol. 2011;40:885-901. http://dx.doi. org/10.1093/ije/dyr050

6. Follow-up to the Political Declaration of the High-level Meeting of the General Assembly on the Prevention and Control of Non-Communicable Diseases [homepage on the internet]. Geneva, Switzerland: World Health Assembly; 2013 [cited 2015 Dec 23]. Available from: http://apps.who.int/gb/ebwha/pdf_files/ WHA66/A66 R10-en.pdf

7. Mayosi BM, Flisher AJ, Lalloo UG, et al. The burden of non-communicable diseases in South Africa. Lancet. 2009;374:934-947. http://dx.doi.org/10.1016/S01406736(09)61087-4

8. Ziraba A, Fotso J, Ochako R. Overweight and obesity in urban Africa: A problem of the rich or the poor? BMC Public Health. 2009;9:465. http://dx.doi. org/10.1186/1471-2458-9-465

9. Puoane T, Steyn K, Bradshaw D, et al. Obesity in South Africa: The South African demographic and health survey. Obes Res Clin Pract. 2002;10:1038-1048.

10. Alaba OA, Chola L. Prevalence of age-adjusted obesity in South Africa and the influence of social determinants: An ecological analysis. Lancet. 2013;381:S6. http://dx.doi.org/10.1016/S0140-6736(13)61260-X

11. Garrow JS. Obesity and related diseases. London: Churchill Livingstone, 1988; p. 1-16.

12. WHO. Obesity: Preventing and managing the global epidemic Report of a WHO Consultation (WHO Technical Report Series 894) [homepage on the internet] [cited 2015 Dec 23] Available from: http://www.who.int/nutrition/publications/ overweight/obesity/WHO_TRS_894/en/

13. Bacopoulou F, Efthymiou V, Landis $G$, et al. Waist circumference, waist-to-hip ratio and waist-to-height ratio reference percentiles for abdominal obesity among Greek adolescents. BMC Pediatr. 2015;15:50. http://dx.doi.org/10.1186/s12887015-0366-z

14. Akintunde AA. Epidemiology of conventional cardiovascular risk factors among hypertensive subjects with normal and impaired fasting glucose. S Afr Med J. 2010;100:594-597. http://dx.doi.org/10.7196/SAMJ.3180

15. Cornier MA, Despres JP, Davis N, et al. Assessing adiposity: A scientific statement from the American Heart Association. Circulation. 2011;124:1996-2019. http:// dx.doi.org/10.1161/CIR.0b013e318233bc6a

16. InterAct C, Langenberg C, Sharp SJ, et al. Long-term risk of incident type 2 diabetes and measures of overall and regional obesity: The EPIC-InterAct case-cohort study. PLoS Med. 2012;9:e1001230. http://dx.doi.org/10.1371/journal.pmed. 1001230

17. Castillo C, Carnicero JA, de la Torre MA, et al. Nonlinear relationship between waist to hip ratio, weight and strength in elders: Is gender the key? Biogerontology. 2015;16(5):685-692. http://dx.doi.org/10.1007/s10522-015-9582-z

18. Dietz WH, Baur LA, Hall K, et al. Management of obesity: Improvement of healthcare training and systems for prevention and care. Lancet. 2015;385(9986):25212533. http://dx.doi.org/10.1016/S0140-6736(14)61748-7

19. Blane DN, Macdonald S, Morrison D, et al. Interventions targeted as primary care practitioners to improve the identification and referral of patients with co-morbid obesity: A realist review protocol. Syst Rev. 2015;4:61. http://dx.doi.org/10.1186/ s13643-015-0046-y

20. Starfield B, Shi L, Macinko J. Contribution of primary care to health systems and health. Milbank Q. 2005;83:457-502. http://dx.doi.org/10.1111/j.1468-0009. 2005.00409.x

21. NHS Health Scotland: Health promoting health service [homepage on the internet]. 2009. [cited 2015 Dec 23] Available from: http://www.healthscotland. com/documents/3274.aspx

22. RCP. Action on obesity: Comprehensive care for all [homepage on the internet] London: Royal College of Physicians; 2013 [cited 2015 Dec 24]. Available from: https://www.rcplondon.ac.uk/projects/outputs/action-obesity-comprehensivecare-all

23. Tomiyama AJ, Finch LE, Belsky ACl, et al. Weight bias in 2001 versus 2013 Contradictory attitudes among obesity researchers and health professionals. Obesity. 2015;23(1):46-53.

24. Sodjinou R, Bosu W, Fanou N, et al. Nutritional training in medical and other health professional schools in West Africa: The need to improve current approaches and enhance training effectiveness. Global Health Action. 2014;1-9. http://dx.doi.org/10.3402/gha.v8.29415

25. Duncan PR, Howe LD, Manukusa Z, et al. Determinants of obesity and perception of weight in hypertensive patients in rural South Africa. S Afr J Clin Nutr. 2014;27(2):56-62. http://dx.doi.org/10.1080/16070658.2014.11734488

26. Malan Z, Mash B, Everett-Murphy K. Development of a training programme for primary care providers to counsel patients with risky lifestyle behaviours in South Africa. Afr J Prm Health Care Fam Med. 2015;7(1):Art. \#819, 1-8. http://dx.doi. org/10.4102/phcfm.v7i1.819

27. Malan Z, Mash B, Everett-Murphy K. Evaluation of a training programme for primary care providers to offer brief behaviour change counselling on risk factors for non-communicable diseases in South Africa. Patient Educ Couns. 2016; 99(1):125-131. http://dx.doi.org/10.1016/j.pec.2015.08.008

28. HPCSA Registrations 2013 [homepage on the internet]. [cited 2015 Dec 12] Available from: http://www.hpcsa.co.za/Registrations/Criteria

29. Al-Ghawi A, Uauy R. Study of knowledge, attitudes and practices of physicians towards obesity management in primary health care in Bahrain. Public Health Nutr. 2009;12(10):1791-1798. http://dx.doi.org/10.1017/S1368980008004564 
30. Cook TD, Campbell DT. Quasi-experimentation: Design and analysis issues for field settings. Boston, MA: Houghton Mifflin Company; 1979.

31. Pati S, Hussain MA, Swain S, et al. Development and validation of a questionnaire to assess multimorbidity in primary care: An Indian experience. BioMed Res Int. 2016;2016: 1-9.

32. Wadden $\mathrm{TA}$, Webb VL, Moran $\mathrm{CH}$, et al. Lifestyle modification for obesity. Circulation. 2012;125(9):1157-1170. http://dx.doi.org/10.1161/CIRCULATIONAHA. 111.039453

33. NHLBI Obesity Education Initiative Expert Panel on the Identification, Evaluation, and Treatment of Obesity in Adults (US). Clinical guidelines on the identification, evaluation, and treatment of overweight and obesity in adults: The evidence report [homepage on the internet]. Bethesda, MD: National Heart, Lung, and Blood Institute; 1998 [cited 2016 June 27] Available from: http://www.ncbi.nlm. nih.gov/books/NBK2004/

34. Sartorius B, Veerman LJ, Manyema $M$, et al. Determinants of obesity and associated population attributability, South Africa: Empirical evidence from a national panel survey, 2008-2012. PLoS One. 2015;10(6):e0130218. http://dx.doi. org/10.1371/journal.pone.0130218

35. Block JP, De Salvo KB, Fisher WP. Are physicians equipped to address the obesity epidemic? Knowledge and attitudes of internal medicine residents. Prev Med.

36. Mariani $S$, Watanabe $M$, Lubrano $C$, et al. Interdisciplinary approach to obesity [homepage on the internet]. [cited 2015 Dec 26] Available from: http://link. [homepage on the internet]. [cited 2015 Dec 26] Available
springer.com/chapter/10.1007/978-3-319-09045-0_28\#page-1

37. Blackburn $M$, Stathi $A$, Keogh $E$, et al. Raising the topic of weight in general practice: Perspectives of GPs and primary care nurses. BMJ Open. 2015;5:e008546. http://dx.doi.org/10.1136/bmjopen-2015-008546

38. Schmidt SL, Bryman D, Greenway FL, et al. How physician obesity medicine specialists treated obesity before 2012 new drug approvals. Obes Surg. 2015 25:186-190. http://dx.doi.org/10.1007/s11695-014-1466-9

39. Standard treatment guidelines and essential medicines list for South Africa. Primary health care level, 2014 edition [homepage on the internet]. [cited 2016 Jul 26] Available from: http://www.up.ac.za/media/shared/62/ZP_Files/standardtreatment-guidelines.zp66671.pdf

40. Owen SE, Sharp DJ, Shield JP. The Bristol online obesity screening tool: Experience of using a screening tool for assessing obese children in primary care. Prim Health Care Res Dev. 2011;12:293-300. http://dx.doi.org/10.1017/S1463423611000132
41. Gance-Cleveland B, Gilbert LH, Kopanos T, et al. Evaluation of technology to identify and assess overweight children and adolescents. J Spec Pediatr Nurs. 2010;15:72-83. http://dx.doi.org/10.1111/j.1744-6155.2009.00220.x

42. Smith AJ, Skow A, Bodurtha J, et al. Health information technology in screening and treatment of child obesity: A systematic review. Pediatrics. 2013;131:e894902. http://dx.doi.org/10.1542/peds.2012-2011

43. Ferrante JM, Piasecki AK, Ohman-Strickland P, et al. Family Physicians' practices and attitudes regarding care of extremely obese patients. Obesity (Silver Spring) 2009;17(9):1710-1716. http://dx.doi.org/10.1038/oby.2009.62

44. Nelson JM, Vos MB, Walsh SM, et al. Weight management-related assessment and counseling by primary care providers in an area of high childhood obesity prevalence: Current practices and areas of opportunity. Child Obes. 2015; 11(2):194-201. http://dx.doi.org/10.1089/chi.2014.0052

45. Sarwer DB, Moore RH, Lisa K, et al. The impact of a primary care-based weight loss intervention on quality of life. Int J Obes (Lond). 2013;37(Suppl 1):S25-S30.

46. Jackson SE, Wardle J, Johnson F, et al. The impact of a health professional recommendation on weight loss attempts in overweight and obese British adults: A cross-sectional analysis. BMJ. 2013;3:e003693

47. Keller C, Ainsworth B, Records K, et al. A comparison of a social support physical activity intervention in weight management among post-partum Latinas. BMC activity intervention in weight management among post-partum Latinas. BMC
Public Health. 2014;19(14):971. http://dx.doi.org/10.1186/1471-2458-14-971

48. Wang ML, Pbert L, Lemon SC. Influence of family, friend and coworker social support and social undermining on weight gain prevention among adults. Obesity (Silver Spring). 2014;22(9):1973-1980. http://dx.doi.org/10.1002/oby.20814

49. Ma J, Strub P, Xiao L, et al. Behavioural weight loss and physical activity intervention in obese adults with asthma. A randomised trial. Ann Am Thorac Soc. 2015;12(1):1-11. http://dx.doi.org/10.1513/AnnalsATS.201406-2710C

50. Lavie CJ, Alpert MA, Ventura HO. Risks and benefits of weight loss in heart failure. Heart Failure Clin. 2015;11:125-131. http://dx.doi.org/10.1016/j.hfc.2014.08.013

51. Jackson SL, Long $Q$, Rhee MK, et al. Weight loss and incidence of diabetes with the Veterans Health Administration MOVE! Lifestyle change programme: An observational study. Lancet Diabetes Endocrinol. 2015;3(3):173-180. http://dx. doi.org/10.1016/S2213-8587(14)70267-0

52. Rurik I, Torzsa P, llyés I, et al. Primary care overweight/obesity management in Hungary: Evaluation of the knowledge, practice and attitudes of family physicians. BMC Fam Pract. 2013;14:156. http://dx.doi.org/10.1186/1471-2296-14-156 